\title{
Language Center Design ANd Management in the Post-Language LABORATORY ERA
}

\author{
Felix A. Kronenberg \\ Rhodes College
}

\begin{abstract}
This article is based on a survey sent to the IALLT membership and to members of all regional groups. Divided into 3 sections titled "Personal," "Profession/Organization" and "Language Center," the survey aims to provide an understanding of current trends and issues in the field of language learning and technology, language center design, and language center management. Findings from the survey reveal a diverse field that differs greatly from institution to institution, one that is trying to adapt to disruptive technological and pedagogical changes and to balance relatively stable physical spaces and structures with rapidly changing and unstable technological and educational environments.
\end{abstract}

\section{INTRODUCTION}

The language center continues to undergo profound changes as digital technologies emerge and mature. While its predecessor, the language laboratory, had a clearly defined mission and purpose, current models of language centers 
are multi-purpose spaces that manifest themselves in very distinct ways at different institutions and locations. The position of the language lab/center director has also changed and there are now different profiles, responsibilities, affiliations, and expectations of those running language centers and those working in or for them as opposed to the language lab. This article is based on a large and comprehensive survey of those working in the field. The survey included questions about personal, professional, organizational and language center related issues. Based on this data and other recent research in the fields of language center design and management, this author argues that the field has expanded in the post-language laboratory era and that it has expanded beyond its core mission from the audio-lingual and pre-internet era. He posits that language centers and the people and organizations connected to them must change and adapt in order to stay relevant. Several recommendations based on the survey and recent research are given at the end of the article.

\section{OVERVIEW}

The history of the language laboratory/center is well documented (e.g. Roby, 2004; Salaberry, 2001; Hocking, 1964). Early laboratories emerged in the first half of the 20th century, but the major proliferation of language laboratories took place in the late 1950s and early 1960s. The four-year National Defense Education Act of 1958 (extended in 1964) made matching funds for purchases of equipment available to U.S. educational institutions (Hocking, 1964), and the growing interest in new second language acquisition theories led to the language laboratory's rapid rise (Salaberry, 2001). Its single mission of providing audial and oral technology support, however, was not sufficient for its long term success. Dakin (1973) argues several years after the language lab's golden age that "[f]ar from being well-established, the role and value of the language laboratory has still to be determined" (p. 1).

The role of personnel working in the language lab has been even less defined and continues to be as the data in this survey suggests. Gopalakrishnan, Yaden, \& Franz (2013) posit that "[r] esearch on the role of LLCs in language learning is at best meager, and there is even less that has been published on the function of the LLC director" (p.1). The survey is meant to provide more data for researchers and collect responses in a systematic way to be able to provide more than anecdotal evidence concerning the state of the field. 
Kronenberg

\section{The STUdY}

The purpose of this survey was threefold: to determine the current roles of personnel working in language centers or in closely related roles, to assess the state of language centers, their design, purposes, and management, as well as to investigate the role of the professional and academic organizations that have traditionally supported language laboratories/centers, such as IALLT and its regional affiliates.

Data from similar surveys is not consistent and rather sporadic. The last data set is from almost ten years ago (International Association for Language Learning and Technology, 2005), and it mostly contains quantitative data. The survey discussed here was designed to be administered on an annual basis in order to gather data about trends and directions and correct for the lack of data.

\section{Data Collection}

The survey was sent out in May 2013 to the IALLT membership and to members of all regional groups. The survey tool used to gather was qualtrics.com. The survey included 53 questions and was divided into 3 sections titled "Personal," "Profession/Organization" and "Language Center."

The third part titled "Language Center" made use of a smart logic algorithm to exclude participants who were not in charge of their language center at the time of the survey. $86 \%$ of those who started the survey finished it completely (127 started, 109 finished the survey).

The complete data set will be available at iallt.org (login required).

\section{RESULTS}

\section{Personal}

The vast majority of respondents are salaried and full time employees. About half $(n=63)$ of those worked for public institutions and about half $(n=62)$ for private ones. Most come from educational institutions that grant at least a bachelor degree. Participants from K-12 made up only $7.58 \%$ and those from community colleges $3.03 \%$. Job titles vary considerably, but there are some 
common title conventions: many staff positions are called director, coordinator, or specialist. Generally the name of the language center is added. For those who teach, another title is often used in addition to a staff title (e.g. lecturer or instructor). For faculty, titles usually include assistant, associate, or (full) professor in addition to administrative titles. $46 \%$ of respondents have a Master's degree, $45 \%$ have a $\mathrm{PhD} .31 \%$ are required to conduct research, and $45 \%$ are expected to present at conferences. $39 \%$ of respondents are faculty. $26 \%$ percent are tenured, but only $2 \%$ are on the tenure-track. Thus, $11 \%$ appear to be in nontenure track/tenure lines.

Survey participants come from a large number of academic fields. Most come from "Foreign Language Literature" (37\%), "Linguistics (Applied and Foreign Language)" (13\%), and "Foreign Language Pedagogy" (10\%). Only 3\% have an instructional technology background. Overall job satisfaction is high (mean=8.13). Dissatisfaction comes from a range of reasons. While some of these are individual and situation specific, some common trends can be ascertained from the survey:

\section{Recognition by institution and colleagues}

While only a few respondents reported that they have to justify the existence of the center ("My College questions the value of our Language Center every few years"), many wrote that a major concern is that it is difficult to reach faculty. One respondent writes, for example, that " $[t]$ he foreign language faculty tend to forget that I have specialized expertise and can help them." Another reports: "I receive more support from the non-tenured faculty than the tenured faculty." The division between tenured/tenure-track faculty and staff as well as contingent faculty is repeatedly found in the responses of several respondents.

Several speak of the lack of recognition as a peer. There are reports of the "stigma of being an 'adjunct instructor"" or of having a "second-caste status in the department." Another respondent writes that "[a]djunct faculty is treated as second class faculty. there [sic] isn't much comunicaton [sic] with the full timers except a very few exceptions." This division can also lead to financial disadvantages for staff: "there is a marked division between the financial support given to tenure/tenure-track faculty and 'teaching' faculty." One respondent states that "a non-tenured person wouldn't be able to do this community building on this campus in the same way. We tried this in the past, but these people weren't taken as seriously." But when tenured or tenure-track, respondents report 
that the workload may be an issue (one reports " 1 course release per year just isn't enough").

\section{Support and responsibilities}

Dissatisfaction also resulted from fewer staff members but more demand and responsibilities, as well as a lack of financial and administrative support. Finances were reported to be both an issue for the language center or for projects ("I basically stay low profile to avoid notice of budget-cutters") but also for personal salaries: lack of salary raises and even declines were reported. The majority of respondents, however, have access to funds to travel to conferences and workshops: $72 \%$ receive travel funding without the need to present, $15 \%$ have to present in order to get travel funding.

A general sense of insecurity and an ill-defined position also contributed to dissatisfaction. One respondent writes: "I would be more satisfied if the position were more defined and the position more secure." This sentiment was expressed several times. Another person laments the lack of a career path or upward mobility and speaks of a "dead-end position."

Among the biggest concerns of respondents are an uncertainty of the mission and future of their centers and individuals' split appointments (having to teach, conduct research, innovate, manage a center, etc., especially in smaller language centers). One respondent asks: "I would like to know what is typical of a small liberal arts institution with limited funding and really only working part time in the LRC."

\section{Profession/Organization}

Several answers in the previous section reflect the sentiment of being rather alone on campus. The need to connect with colleagues, peers, professionals and academics in their fields is an important part of organizations, such as IALLT and its regional affiliates. $56 \%$ of respondents are not in a regional group affiliated with IALLT. Overall, only 4\% indicated that IALLT doesn't provide the information, services, and networking opportunities one would expect from such an organization. 57\% have a need for language center management and/or design resources and information; for about half of respondents (52\%), IALLT does provide this, $10 \%$ indicated that IALLT does not. $34 \%$ of respondents stated that they would like to be involved with IALLT, and the same number responded 
that they don't know how to become involved. The necessity of updating the key publications, Language Center Design and the Management Manual were stressed. Both publications were recently updated.

Several respondents indicated needs that are currently not fulfilled by IALLT. Because language centers and institutions can differ so greatly from one another (Kronenberg, 2011b), different professionals have different needs. One respondent requested to provide resources that are catered to the different sizes and communities our centers support (small liberal arts colleges, large research institutions, $\mathrm{K}-12$, etc.). One respondent would like to have a buyer's guide with product reviews provided through IALLT. Another would like to have more regular communication with quickly accessible information.

\section{Language Center}

$58 \%$ of respondents are in charge of their language center. The following percentages refer only to those in this group. (The survey ended at this point for respondents who are not in charge of a language center). The majority report having one staff member or less than that (e.g. a split position or complete reliance on student staff). 5 centers reported having 3 staff members, and one center employs 7, another 8, and another 9 staff members. Most centers rely heavily on student workers.

$59 \%$ of centers are part of a language department, $12 \%$ are independent, and others are part of a college, the library or ITS. One center $(2 \%)$ is part of a Teaching/Learning Center/Commons. There is not a single service that every language center provides, and answers reflect the growing trend that language centers are not as well defined as language laboratories were. The most common services and responsibilities of language centers are: "Classroom instruction" (71\%), "Special services" (52\%), "Facilitate project work" (72\%), "Provide online spaces" (57\%), "Provide non-traditional spaces" (53\%), "Provide social spaces" (52\%), "Provide event spaces" (50\%), "Plan events" (28\%), "Provide professional development" (59\%), "Technological support" (76\%), "Hardware and equipment maintenance" (38\%) and "Provide support for languages not taught at your institution" (29\%).

Even though many responded that progress in their centers was slow or nonexistent, there were also examples of new designs and redesigns as well as completely new centers. Most respondents reported having complete or partial redesigns in recent years. Answers indicate that language centers continue to 
evolve. The size of $67 \%$ of centers is adequate to fulfill their mission according to those in charge of their centers. The majority of centers, $64 \%$, are not assessed or evaluated on a regular basis.

There were many positive aspects reported about respondents' language centers, and many are very specific to their location, institution, and location. Answers indicate that because of rapidly changing needs, most centers are trying to keep up with new demands and changed realities. One respondent writes: "Concerns: To remain relevant." Another sums up these current trends and warns of the danger of reducing the center's mission: "As we move to a more mobile, wireless world, with most applications being available on the Web, we need to continually redefine our focus while fulfilling our mission of supporting the teaching and learning of languages with technology. We need to remain up-todate on effective use of available tools and continue to explore options to improve language programs. I would like to avoid being reduced to a testing center and prefer to lead the efforts to explore possibilities for using technology to access information and to enhance communication."

Flexible spaces as well as multi-purpose centers were mentioned as safeguards against the uncertainty of technological, pedagogical, and institutional developments. A trend towards more social and collaborative spaces and away from a technology center was also mentioned several times. One respondent writes: "The biggest challenge is the changing nature of technology, from specialized, established hardware and spaces to integrating personal technology. Movement seems to be from individualized learning in carrels to collaborative spaces and areas where both personal technologies can be used with stationary equipment. How to determine the ratio of personal space with collaborative space is difficult. Also, getting the faculty to think about the center differently than in the past as a place where the technology was. New ideas of integration need to be thought through." The trend towards more social and collaborative spaces, however, is not always received positively, especially when the institution is nonresidential: "Being a commuter school, students do not "hang around" to engage in social activities. The bulk of our faculty are PTIs who also leave as soon as they are finished teaching. This does not promote social gathering in the lab."

The changing nature of language centers is also reflected in changed positions of those working in them. Many answers about the challenges that language centers face mirror those about personal satisfaction (see above): financial limitations, lack of interest, understanding, or need from language 
faculty and sometimes students, efforts to centralize services and create efficiencies on campus, technical support, recognition and lack of understanding of the center's work across campus, inadequate staffing, split appointments, keeping up with technological changes, inadequate locations (e.g. at the edge of campus or in a basement) or lack of space.

Remaining relevant appears to be the most fundamental challenge. One respondent writes: "I am uncertain whether we still need a language center. For awhile [sic], we thought of hiring someone with foreign language and technological skills. Now, textbooks come with so many ancillaries and online instruction seminars by the institution provide individual help to teachers."

\section{DISCUSSION}

Language centers are considerably different from one another. Some are very large entities; others only consist of one room. Some are staffed with several fulltime professionals; others are managed by faculty or staff with split appointments and mostly run by student staff. The term "language center" is very vague and seems to mean different things to different people and at different institutions. Therefore, it is difficult to get a complete picture from this survey. There are, however, some general trends have become clear from the answers:

1. an ever changing environment, in which innovation in technology and pedagogy force language technology professionals to continuously adapt and carefully plan for an uncertain future. A centers mission is constantly changing and needs to adapt to these new realities

2. there is a need for the physical spaces that language centers provide to change in this environment, but this is difficult because of building cycles, planning procedures, and different expectations from different stakeholders

3. the role of the language center director and its staff are increasingly less defined, secure, and often lack a clear identity

\section{Changing environment and mission}

The mission of language centers is constantly shifting and changing. For one, new technologies and pedagogies demand new services and support systems. For example, a few years ago, powerful, dedicated computers were a must for video 
editing. Nowadays, much of this can be done on low-end machines and increasingly on mobile devices. Language centers had to provide dedicated hardware and software for many applications, but as cloud-computing plays an ever more important role, there has been a shift to license management and more focus on pedagogical rather than technical issues. The sheer number of new developments makes it impossible for individuals to remain knowledgeable about every tool and development, and not every new tool or application can be tested and supported by every language center.

As the survey showed, the term language center is much more vague than its predecessor, the language lab. Labs were limited to few and fairly well defined types of activities. Even though Hocking (1964) notes that the term language lab "has become almost generic and has at times been used to mean an idea, a method, a technique, a special room, a machine, or various types of electronic systems" (p. 29), it was generally understood what was meant by the term, and was relatively comparable from institution to institution.

Such labs were closely tied to the audio-lingual instructional method (ALM), which is nowadays only one of many functions of a language center. Askildson (2011) argues that many centers today are still based on the ALM and have not sufficiently re-defined their mission:

And although such labs have certainly not remained static in terms of their technologies and varieties of support, many remain closely tied to a role of serving as a language resource. A role that is necessarily ancillary to the contemporary focus on communicative language learning and one which ignores the potential for language labs to play a significantly more prominent and substantive role within their institutions in the form of language centers and the 'language learning community' that such a designation connotes. (p. 12)

He goes on to describe potential roles of language centers that would position them well in today's changing educational environment and posits that centers that take on these roles are "almost unrecognizable" from more traditional labs. He sees more modern centers promoting "a dynamic language learning community emphasizing interactive programming and emerging technologies that bridge the gap between the center and the foreign language classroom" (Askildson, 2011, p. 19). Extending and defining the center's mission may be the most urgent tasks that today's centers face, and this survey reflects the variety of 
possible uses, goals, and challenges. This is an ongoing process and a center's survival may depend on it. Liddell and Garrett (2004) warn that "language labs that grew out of the classical humanistic tradition may be situated outside the main campus technology support system. Thus, they may exist as stand-alone units and be vulnerable to elimination or takeover by academic computing" ( $p$. 33). The more other offices and units provide services that language labs/centers traditionally provided even until recently, the more the labs/centers have to adapt to these changed realities. One respondent in the survey remarked: "The downside to this is that publishing companies have created similar sites for their textbooks and that has eaten into our server usage." Audio and video streaming, something that has been routinely provided by language centers, has suddenly become a mostly obsolete responsibility. What might fill its place?

As many respondents wrote, a move to more social spaces is one possible answer, and this is often based on learning theories that see learning not as purely cognitive but also social. For example, following Vygotskian thought, Lave and Wenger (1991) assert that learning is situated, meaning that knowledge is co-constructed. In their view, learning does not only take place in formal teaching and learning spaces, such as classrooms and language centers. This view of learning differs greatly from the idea of the language lab/center as being a centralized learning location. Rather, it ought to be seen as a hub than can provide connections, support, and social spaces to enable various forms and contexts of language learning and allows learner to become part of a community of learners and practitioners. In this view, language centers offer an environment that provides specific contexts for language learning.

Language centers that have not been updated or redesigned in recent years, however, are not set up to provide spaces to build communities of learners. Wang (2006) rightly asks: "Since more and more computer technology is available even in the far reaches of the student dorms, what draws students to still make use of the LLC?" (p. 57). Answers from the survey reflect the sentiment that many centers are underused and that they should become more social. $52 \%$ of centers "[p]rovide social spaces" according to the survey, so this appears to be one area into which centers may invest in the future. What social space means will have to be determined by each institution individually as this kind of design work is situated, that is to say it is embedded in the individual educational and institutional context. 
Kronenberg

\section{Physical space}

In general the survey yielded many positive examples, trends, and features in language centers: these include flexibility, adaptability, and a focus on people. Successful centers appear to share the characteristics of being a communal space and of having good support and buy-in from faculty and administration. Also, those centers that are constantly adapting to new trends and not remaining static are working well.

Translating these features into physical space design is complex, and resources from IALLT, such as the IALLT Language Center Design publication (Kronenberg, 2011a), language center design workshops, and hiring a consultant can be effective aids. But breaking with the past of the language lab/center and moving to a new design needs a very different approach than lab design in the past. Wenger, McDermott, and Snyder (2002) state that community design "is much more like life-long learning than traditional organization design. 'Alive' communities reflect on and redesign elements of themselves throughout their existence. Community design often involves fewer elements at the beginning than does a traditional organization design" (p. 53). In an unpredictable future, this advice is in line with the other two trends, flexibility and adaptability, but it is unfortunately not how most design processes at educational institutions work. Usually, a building or space is planned completely in the beginning, and followup design is given little thought thereafter. Funding also follows this pattern: often there is a larger sum available when construction happens, but a lot less in subsequent years after construction has been completed.

These trends in language center design can be found in space design work in general.

Architecture, Kroll (1984) argues, "is an instrument that can encourage or block human behaviors - all the more powerful because its language is addressed to the unconscious. If it is designed entirely by specialists, if it is fixed and untouchable, it cannot possibly respond to the diversity and creativity of those who use it" (p. 167). This supports the need to involve the space's actual users: faculty, students, and staff. Grosvenor and Burke (2008) posit that architects generally are not able to use and observe the spaces they plan, which makes it even more important to involve the language center's users in the design process.

The question remains whether providing social spaces, or to borrow from Oldenburg (1999), third places, is enough to justify the existence of a 
language center, especially at smaller institutions. This author argues that clearly centers need to provide unique services for the teaching and learning of languages, should make sure to communicate them to their users, and be prepared to constantly change and evolve.

\section{Role of the Director Role and Staffing}

The person in charge of the language center, most often called the director (and thus henceforth referred to as the director), has traditionally been in a somewhat difficult situation. The survey reflects this. For one, the director is usually alone in that role on campus. Professional networks and support are important for that reason alone. The faculty/staff split continues to be a problem at many institutions. A decade ago, Liddell and Garrett (2004) summed up the situation:

Language lab directors are often thought of as staff, not faculty, and are seen as managers of student workers and providers of the routine services demanded of them by teachers (though they often teach language classes themselves as part of their responsibilities. Direct access to higher administrators or senior faculty in the LL\&C departments may be problematical. In short, they may lack a strong political voice at the academic table. (p. 33)

The MLA proposes that departments and faculty should not only acknowledge staff members as "vital collaborators," but also themselves become more involved in experimentation with new information technologies (Modern Languages Association, 2013). Franz calls the multiple roles of a language center director a "balancing act" and provides a number of job profiles: hands-on technician, educational technologist, policy maker, financial analyst, evangelist, and manager (Gopalakrishnan, Yaden, \& Franz, 2013, p. 13). There are many other roles than might be added at different institutions, such as instructor or researcher. Gopalakrishnan proposes nine steps for effective directors as "change agents": creating a vision and goals, drafting a strategic plan, motivating technology integration, communicating vision and goals, developing political support, managing the transition, measuring outcomes, ensuring quality, and sustaining the integration of technology" (Gopalakrishnan, Yaden, \& Franz, 2013 , p. 4). Indeed, because of the many, often changing responsibilities, Liddell and Garrett (2004) speak of a new mandate for language center directors, one that goes beyond providing technical support. Half a century ago, Turner (1964) 
proposed a "a new breed of Language Laboratory Director who can bring to his job a true professional status" (p. 151). The director was supposed to not only work as technology support staff, but have "considerable experience as a second language teacher and learner" (p. 151) and be charged "not only with the collection of currently available information, but also with the development of new methods, equipment and techniques" (p. 152). As the role of the language center changes, rethinking staffing status and responsibilities will be an integral part of this transformational process. Elevating the academic profile of language center staff, especially those directing the center, might be difficult because of a lack of suitable graduate programs.

\section{CONCLUSION}

Based on this survey and other recent research in the fields of language center design and management, this author argues that the field has diffused in the post-language laboratory era and that language centers and the people and organizations behind them must change and adapt in order to stay relevant.

Continued research is necessary to assess what changes are happening in language centers and in what ways they are adapting. The IALLT survey will be conducted on an annual basis to not only gather more raw data for researchers, but also to be able to ascertain information about trends in language center design, management, as well as developments in technology and pedagogy. Some questions that continued research should shed light on and find answers to include: How do faculty and language center staff become change agents? What functions and mandates of language centers decline or disappear, and which emerge? What is the role of language centers in an environment in which most tenured and tenure-track language professors "were trained exclusively in literary criticism but might do as much as two thirds of their teaching in language classes" (Liddell and Garrett, 2004, p. 33)? And more fundamentally: are language centers disappearing and being absorbed into larger, more centralized structures in educational institutions, or is there a countertrend to these developments?

This author argues that language centers should not so much be driven by technology, which is difficult to predict and support, but rather focus on pedagogical innovation and development, of which technology may be an integral part. By doing so, language centers may be able to gain more agency and 
influence and be less prone to technological disruptions, helping to set the stage for a transformed language center.

\section{About the Author}

Dr. Felix Kronenberg is an as Assistant Professor for Modern Languages and Literatures and Director of the Language Learning Center at Rhodes College. He was awarded the 2009 Marie Sheppard Award by the International Association for Language Learning and Technology, and has been a fellow for the National Institute for Technology in Liberal Education. He is the immediate past-president of SWALLT and the editor of the IALLT Book Language Center Design. 
Kronenberg

\section{REFERENCES}

Askildson, L. R. (2011). From lab to center: A vision for transforming a language learning resource into a language learning community. In F. A. Kronenberg (Ed.), Language Center Design (pp. 11-22). International Association for Language Learning and Technology.

Dakin, J. (1973). The language laboratory and language learning. London: Longman.

Garrett, N., \& Liddell, P. (2004). The new language centers and the role of technology: New mandates, new horizons. In S. Fotos \& C. Browne (Eds.), New perspectives on CALL for second language classrooms (pp. 27-40). Mahwah, NJ: L. Erlbaum Associates.

Gopalakrishnan, S., Yaden, B., \& Franz, J. (2013). Management and leadership: Roles, styles and philosphies. In A. F. Ross (Ed.), Language center management (pp. 1-15). International Association for Language Learning and Technology.

Grosvenor, I., \& Burke, C. (2008). School. London: Reaktion Books.

Hocking, E. (1964). Language laboratory and language learning. Washington D.C.: Dept. of Audiovisual Instruction, National Education Association of the United States.

International Association for Language Learning and Technology. (2005). The 2005 IALLT survey of the profession. IALLT Journal, 38(1), 15-48.

Kroll, L. (1984). Anarchitecture. In C. R. Hatch (Ed.), The Scope of social architecture (pp. 166-181). New York, NY: Van Nostrand Reinhold.

Kronenberg, F. A. (Ed.). (2011a). Language center design. Moorhead, MN: International Association for Language Learning and Technology.

Kronenberg, F. A. (2011b). Language centers at small institutions. In F. A. Kronenberg (Ed.), Language Center Design (pp. 83-94). International Association for Language Learning and Technology.

Lave, J., \& Wenger, E. (1991). Situated learning: Legitimate peripheral participation. Cambridge, U.K.: Cambridge University Press. 
Oldenburg, R. (1999). The great good place: cafés, coffee shops, bookstores, bars, hair salons, and other hangouts at the heart of a community. New York, NY: Marlowe; Distributed by Publishers Group West.

Roby, W. B. (2004). Technology in the service of foreign language learning: The case of the language laboratory. In Handbook of research on educational communications and technology (2nd ed., pp. 523-541). Mahwah, NJ: Lawrence Erlbaum.

Salaberry, M. R. (2001). The use of technology for second language learning and teaching: A retrospective. The Modern Language Journal, 85(1), 39-56.

Wang, J. (2006). The changing role of a language learning center at a liberal arts college in the midst of technological development. IALLT Journal, 38(1), $56-65$.

Wenger, E., McDermott, R. A., \& Snyder, W. (2002). Cultivating communities of practice: A guide to managing knowledge. Boston, MA: Harvard Business School Press. 